\title{
WORKING KNACKS AND IMPACT OF EMOTION DISPLAY ON JOB SATISFACTION
}

\author{
Wang Xiaochen ${ }^{1}$, Allan Phiri ${ }^{*}$, Salma Tahseen ${ }^{3}$, Francisca Nyarai Mapiye Dube $^{4}$ \\ ${ }^{1,2}$ School of Business Administration, Zhejiang Gongshang University, Hangzhou,China \\ ${ }^{3}$ New Cambridge Academy, Data Colony, Multan, Pakistan \\ ${ }^{4}$ Xi'an Jiaotong-Liverpool University, China
}

Phiriallan22@yahoo.com

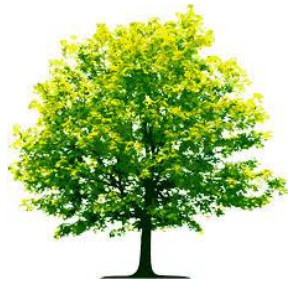

Keywords: Leadership, Emotion Display, Surface Acting, Deep Acting, Job Satisfaction

\begin{abstract}
A B S T RA C T
Emotion management has reached the level of tall standing in the fields of psychology and business management. This article conceptualizes the emotional work develop regarding two variables: surface acting and deep acting produced by communicating hierarchically wanted emotions not truly felt. With the optimal review of literature, this article introduces the ramifications of deep acting and surface following up on the job satisfaction of the employee by the leader. Frequency of emotional display, such as deep acting and surface acting display rules, hypothesized to lead to greater high job satisfaction, lower job satisfaction respectively. There are several theoretical and practical implications which can be drawn from this relationship after testing.
\end{abstract}

Citation: Wang Xiaochen, Allan Phiri, Salma Tahseen, Francisca Nyarai Mapiye Dube (2018). Working Knacks And Impact Of Emotion Display On Job Satisfaction. International Journal of Advanced Multidisciplinary Scientific Research (IJAMSR ) ISSN:2581-4281 Vol 1, Issue 9, November, 2018, \#Art.919, pp 66-70 


\section{Introduction:}

Due to its prime role, emotion management at the workplace has a steady influence on organizational behavior. In work environment, individuals may express their emotions to others around them. There is developing proof that such emotional expressions impact organizational behavior and job satisfaction (Elfenbein, 2007; Hawk, Fischer, \& Van Kleef, 2012)particularly when they are transmitted by leaders. Without any doubt, a few investigations have demonstrated that leaders' emotional presentations can possibly impact followers' performance and motivation, indicating the basic significance of leaders' emotions display is crucial in the organizational achievement and followers endurance(Gooty, Connelly, Griffith, \& Gupta, 2010)

This paper focus on how emotional labor impacts the work behavior. The review and development of Emotional labor literature writing which includes overseeing emotions and emotional expressions to agree to a firms display rulesMorris and Feldman (1997)display rules allude to organizational models that demonstrate which emotional expressions are suitable for the circumstance. Which is the degree to which individuals like fulfillment or aversion disappointment their employments.Choi-Kwon et al. (2012)characterize job satisfaction as understanding followers ' sentiments at the work environment and the amount they like their present calling, which is extremely essential in administration associations. Understanding this significance, numerous behavioral examinations have researched job satisfaction in a few organizations enterprises.

\section{Literature Review}

We define Job satisfaction alludes to "an evaluative express that communicates happiness with and positive emotions about one's occupation"(Judge \& KammeyerMueller, 2012, p. 343) Job satisfaction has two significant parts, specifically emotional sentiments toward one's activity and subjective psychological assessment of one's activity segments (Judge \& Kammeyer-Mueller, 2012) Job satisfaction has been an essential focal point of organizational analysts and experts for quite a long time, because of its effects on an assortment of work environment results described two manners by which workers adjust how they showcase their emotional expressions. Employees change their outward enthusiastic articulations yet don't try to feel the feelings that they are appearing, they are practicing surface acting. Strangely, when they try to truly feel the feelings they have to appear, they are practicing deep acting (Schleicher, Hansen, \& Fox, 2011)

Furthermore, Ashforth and Humphrey (1993) contended that workers additionally perform emotionallabor, to be specific, through unconstrained and certifiable emotion.Chau, Dahling, Levy, and Diefendorff (2009) expressed how thecommunication of normally endured emotions is a viable type of emotional labor.Humphrey (2006)built up the expression "driving with emotional work" to insinuate leaders or diverse managerswho use emotional labor and enthusiastic directions to affect the perspectives, feelings, motivations, and execution of their subordinates or devotees. Notwithstanding the way that follower and diverse subordinates are well while in transit to be affected by discernible enthusiastic introductions, leaders may need to partake in passionate work in order to convey the benefit enthusiastic articulations to move or affect their followers. 


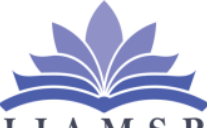

International Journal of Advanced Multidisciplinary Scientific Research (IJAMSR) ISSN:2581-4281

The study of emotions has distinguished two different ways of emotional labor: surface acting and deep acting. The surface is acting insinuates changing noticeable outward articulations, dishonestly showing unfelt feelings and additionally veiling felt feelings. Workers who use surface acting just direct discernible articulations, concealing guaranteed feelings and demonstrating an outward appearance in reliable with bona fide assumptions. For example, lodging, visitor benefit operators may utilize surface acting to maintain a positive front despite disregard and undeserved upsetting news from impolite clients paying little respect to their actual emotions. Research has discovered that surface acting for the most part induces emotional discord, an inside condition of uneasy pressure coming about because of encountering a mental error between certifiable inward inclination and pretended emotion showed (Grandey, 2000).

Deep acting alludes to a functioning exertion to change internal sentiments to align them with a more adequate emotion(Christoforou \& Ashforth, 2015).Instead of acting on the surface, deep acting occurs when workers participate in an effort to control and change their internal assumptions and perceptions to match the feelings that an affiliation requires. In this way, employees who take part in deep acting deliberately endeavor to earnestly under-stand their clients, identify, and feel as clients feel, as though those sentiments were their own. Changing one's emotion c situations may incorporate looking on the positive parts of the condition, contemplating the events that summon a typical feeling, and abstractly reappraising the situation even more unequivocally; these exhibits the passionate work of deep acting (Grandey, 2000).

\section{Emotion-Satisfaction Model}

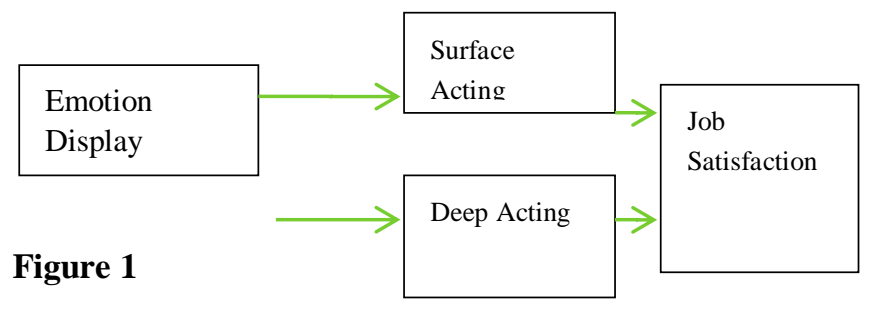

\section{Discussion}

Transformational initiative postulates have given extraordinary thoughtfulness regarding the job of emotional expressiveness. Transformational leaders are described by the accompanying four characteristics: admired impact, helpful inspiration, scholarly incitement, and individualized thought. Being emotionally expressive principally includes the rousing inspiration and individualized thought parts of change authority. We battle that emotional labor can empower leaders to convey their talks and trades all the all the more awakening. In any case, in case leaders place emotions into their exchanges, they are not committed to moving, nor are they slanted to build up an adjusted, association with others. Since leaders are considered followers of professional and social life, they may need additional insight and effort to structure their exchanges to empower them. In other words, they may have to use exciting work to create the associations they have to give.(Banks, McCauley, Gardner, \& Guler, 2016; McCleskey, 2014). Besides the social life of employees, large companies are now inclined to consider social needs of community(Y Hao, Farooq, \& Zhang, 2018).

Emotional laborby leaders will enhance their correspondents, and deep acting will be more viable for social identity than for action on the surface with a broader vision of matching skills (Tyler \& Blader, 2000).The emotional regulation in others can allow 
leaders to know when they should do exciting work, for example, to see when a perplexed worker needs affection or various types of motivation and help to be able to work. Affection, leaders may need to demonstrate intelligence, enthusiastic articulations, perform passionate work. The expressionof one's feelings can allow leaders to do passionate work because enthusiastic work is simply effective if feelings are transmitted in ways that influence collectors through social identity.This expression, especially about social responsibility may become convenient through usage of social media(Yunhong Hao, Farooq, \& Sun, 2018). This may help most when leaders' passionate introductions involve unconstrained and veritable feelings, anyway, it has all the earmarks of being sensible to believe in the expression of one's feelings is an aptitude that may help with every one of the two sorts of emotional labor (Grandey, Rupp, \& Brice, 2015; Pugh, Diefendorff, \& Moran, 2013)

Research on job satisfaction suggests that emotional work has positive and negative results, depending on the type of emotional labor performed by employees. In most cases, previous research has shown that play on the surface produces positive results, such as greater benefits, performance and pleasure at work, while play on the surface produces undesirable results such as depletion and degenerate organizational behavior. For instance, Totterdell and Holman (2003)examine demonstrated that surface acting expands benefit execution more than surface acting. (Lee, Ok, Lee, \& Lee, 2018) found that the workers involved in deep acts are necessarily satisfied with their occupations than the followers who use superficial acts. It is interesting to note that, as noted by Arnold, Connelly, Walsh, and Martin Ginis (2015), acting on the surface causes pressure and stress, poor quality management, burnout, professional deception, and misbehavior in the organization. Grandey (2000)recommended that acting on the surface is an uncomfortable subject in which workers manage their emotions automatically and maintain a positive emotional presentation. This requirement can cause them to feel frustrated at work and, ultimately, to disappoint them with their activity.Speculative musings and proposition highlighted future research consideration (Van Kleef, Homan, \& Cheshin, 2012).

The review consistently lead to the enlistment line specialists and administrators fluctuate in sorts of passionate work and their components of and work fulfillment. For example, line-laborers are less drawn in than chiefs to manage organization disillusionment and customer protests; thusly, line-supporters will undoubtedly feel work disappointment and more questionable experience trademark prizes than supervisors(Aslan \& Kozak, 2012)

\section{Conclusion}

In this review, we showed that expressions of outrage may hamper the inspiration of job satisfaction, particularly when the objective of the emotion sees the resentment as improper. The developing writing with emotions demonstrated that leaders' emotional display may empower the follower'sjob satisfaction and a recognized critical arbitrator, to be specific the apparent stability of the emotional display. In this article, we fight that passionate work require not be reliably hurting or correspondingly hurting to all employees. it is fundamental the complexities of feeling the executives as a noteworthy part of the job in most kinds of work behaviors. 


\section{International Journal of Advanced Multidisciplinary Scientific Research (IJAMSR) ISSN:2581-4281}

\section{References}

1) Arnold, Kara A, Connelly, Catherine E, Walsh, Megan M, \& Martin Ginis, Kathleen A. (2015). Leadership styles, emotion regulation, and burnout. Journal of Occupational Health Psychology, 20(4), 481.

2) Ashforth, Blake E, \& Humphrey, Ronald H. (1993). Emotional labor in service roles: The influence of identity. Academy of management review, 18 (1), 88115.

3) Aslan, Alper, \& Kozak, Metin. (2012). Customer deviance in resort hotels: The case of Turkey. Journal of Hospitality Marketing \& Management, 21(6), 679-701.

4) Banks, George C, McCauley, Kelly Davis, Gardner, William L, \& Guler, Courtney E. (2016). A metaanalytic review of authentic and transformational leadership: A test for redundancy. The Leadership Quarterly, 27(4), 634-652.

5) Chau, Samantha L, Dahling, Jason J, Levy, Paul E, \& Diefendorff, James M. (2009). A predictive study of emotional labor and turnover. Journal of Organizational Behavior, 30(8), 1151-1163.

6) Choi-Kwon, S, Han, K, Choi, S, Suh, M, Kim, Y-J, Song, H, . . . Kang, D-W. (2012). Poststroke depression and emotional incontinence Factors related to acute and subacute stages. Neurology, WNL. Ob013e31824f38090.

7) Christoforou, Paraskevi S, \& Ashforth, Blake E. (2015). Revisiting the debate on the relationship between display rules and performance: Considering the explicitness of display rules. Journal of Applied Psychology, 100(1), 249.

8) Elfenbein, Hillary Anger. (2007). 7 Emotion in organizations: a review and theoretical integration. The academy of management annals, 1(1), 315-386.

9) Gooty, Janaki, Connelly, Shane, Griffith, Jennifer, \& Gupta, Alka. (2010). Leadership, affect and emotions: A state of the science review. The Leadership Quarterly, 21(6), 979-1004.

10) Grandey, Alicia A. (2000). Emotional regulation in the workplace: A new way to conceptualize emotional labor. Journal of occupational health psychology, 5(1), 95.

11) Grandey, Alicia A, Rupp, Deborah, \& Brice, William N. (2015). Emotional labor threatens decent work: A proposal to eradicate emotional display rules. Journal of Organizational Behavior, 36(6), 770-785.

12) Hao, Y, Farooq, Q, \& Zhang, Y. (2018). Unattended social wants and corporate social responsibility of leading firms: Relationship of intrinsic motivation of volunteering in proposed welfare programs and employee attributes. Corporate Social Responsibility \& Environmental Management. doi: https://doi.org/10.1002/csr.1681

13) Hao, Yunhong, Farooq, Qamar, \& Sun, Yuan. (2018). Development of theoretical framework and measures for the role of social media in realizing corporate social responsibility through native and non-native communication modes: Moderating effects of cross-cultural management. Corporate Social Responsibility \& Environmental Management(2). doi. https://doi.org/10.1002/csr.1523

14) Hawk, Skyler T, Fischer, Agneta H, \& Van Kleef, Gerben A. (2012). Face the noise: Embodied responses to nonverbal vocalizations of discrete emotions. Journal of Personality and Social Psychology, 102(4), 796.

15) Humphrey, Ronald H. (2006). Promising research opportunities in emotions and coping with conflict. Journal of Management \& Organization, 12(2), 179. 186.

16) Judge, Timothy A, \& Kammeyer-Mueller, John D. (2012). Job attitudes. Annual review of psychology, 63, 341-367.

17) Lee, JungHoon, Ok, Chihyung "Michael", Lee, Seung-Hoon, \& Lee, Choong-Ki. (2018). Relationship between Emotional Labor and Customer Orientation among Airline Service Employees: Mediating Role of Depersonalization. Journal of Travel Research, 57(3), 324-341.

18) McCleskey, Jim Allen. (2014). Situational, transformational, and transactional leadership and leadership development. Journal of Business Studies Quarterly, 5(4), 117.

19) Morris, J. Andrew, \& Feldman, Daniel C. (1997). Managing emotions in the workplace. Journal of managerial issues, 257-274.

20) Pugh, S Douglas, Diefendorff, James M, \& Moran, Christina M. (2013). Emotional labor: Organizationlevel influences, strategies, and outcomes: Routledge/Taylor \& Francis Group.

21) Schleicher, Deidra J, Hansen, S Duane, \& Fox, Kevin E. (2011). Job attitudes and work values.

22) Totterdell, Peter, \& Holman, David. (2003). Emotion regulation in customer service roles: Testing a model of emotional labor. Journal of occupational health psychology, 8(1), 55.

23) Tyler, Tom R, \& Blader, Steven L. (2000). Cooperation in groups: Procedural justice, social identity, and behavioral engagement: Psychology Press.

24) Van Kleef, Gerben A, Homan, Astrid C, \& Cheshin, Arik. (2012). Emotional influence at work: Take it EASI. Organizational Psychology Review, 2(4), 311 339. 